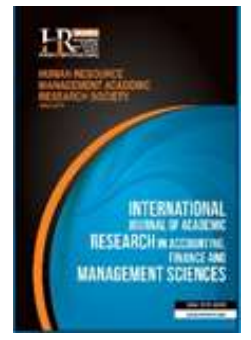

International Journal of Academic Research in Accounting, Finance and Management Sciences

Vol. 9, No.3, July 2019, pp. 346-352

E-ISSN: 2225-8329, P-ISSN: 2308-0337

(c) 2019 HRMARS

www.hrmars.com

To cite this article: Ismail, Z., Ahmad, A.S., Ahmad, N.L., Mahjom, N. (2019). An Analysis of Students' Knowledge

Construction and Their Achievement in a Taxation Subject, International Journal of Academic Research in

Accounting, Finance and Management Sciences 9 (3): 346-352

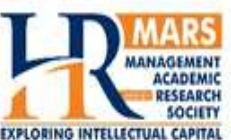

http://dx.doi.org/10.6007/IJARAFMS/v9-i3/6528

(DOI: 10.6007/IJARAFMS/v9-i3/6528)

\title{
An Analysis of Students' Knowledge Construction and Their Achievement in a Taxation Subject
}

\author{
Zuriadah Ismail ${ }^{1}$, Anis Suriati Ahmad ${ }^{2}$, Noor Lela Ahmad ${ }^{3}$, Nurhanie Mahjom ${ }^{4}$ \\ ${ }^{1}$ Faculty of Management and Economics, Universiti Pendidikan Sultan Idris, Tanjong Malim, Perak Malaysia \\ ${ }^{1}$ Email: zuriadah@fpe.upsi.edu.my (Corresponding author)
}

\begin{abstract}
Taking a legal-based paper among the Accounting students is often set as a challenge due to a complexity of legal terms and its application to bring a conceptual and technical knowledge to a real case situation. Being aware of its course natures, determine a knowledge structure would assist the students and course instructor in the development of effective styles of teaching and learning. Guided with the main objective of study to analyze how the Third year of accounting students in a Taxation Class constructed their knowledge by using a semi-structured questionnaire. At the end of the semester, student achievement was measured for describing how students who were successful in this course used effective ways of constructing their knowledge. Based on the analysis, the result shows that a Taxation subject is a hierarchical knowledge structure and to be succeeding in this subject requires a student to acquire a high degree of conceptual and technical knowledge. Given the lens through the student's view validated by what was seen in their examination result. The study outcomes suggests that knowing the structure of knowledge in a particular subject allows students to expand for a student progresses through the course and becomes skilled in various procedures. This adds the value to course instructors for improving pedagogical approach and producing a proper documentation (procedures) for guiding a moderate or less successful student in the various techniques which are required for knowledge construction.
\end{abstract}

Key words Knowledge Structure, Taxation Subject, Accounting Education

\begin{tabular}{|c|c|c|}
\hline Received: & 06 Oct 2019 & (C) The Authors 2019 \\
\hline Revised: & 06 Nov 2019 & Published by Human Resource Management Academic Research Society (www.hrmars.com) \\
\hline $\begin{array}{l}\text { Accepted: } \\
\text { ed Online: }\end{array}$ & $\begin{array}{l}09 \text { Nov } 2019 \\
11 \text { Nov } 2019\end{array}$ & $\begin{array}{l}\text { This article is published under the Creative Commons Attribution (CC BY } 4.0 \text { ) license. Anyone may } \\
\text { reproduce, distribute, translate and create derivative works of this article (for both commercial and } \\
\text { non-commercial purposes), subject to full attribution to the original publication and authors. The full } \\
\text { terms of this license may be seen at: http://creativecommons.org/licences/by/4.0/legalcode }\end{array}$ \\
\hline
\end{tabular}

\section{Introduction}

Uncertainty in the recent economic has led a demand for talent across the industry, however, it remains unstable. This is a conjunction with a published report by the Malaysia Employment Outlook and Salary Guide 2019 which showing that the Malaysia industry needs for quality talent in Accounting professions by 2020. Hence, for that purpose of the human capital development agenda, many education providers take pro-active action to revamp their accounting programme for meeting further capacity of future talents in accounting professions, particularly in taxation areas. Nevertheless, the issue of quality teaching and learning for a law-based subject to accounting students presents a major challenge for the course instructor. Among the indicated challenges to a law subject in accounting is to apply tax knowledge to a real-based situation. Further, the acknowledged issue is to bring a conceptual and technical knowledge into a legal problem-solving skill. This highlights the inability of students to engage with legal materials and bringing the accounting theory to a real case. 
Related discussion about the problem is particularly visible when the accounting students learn a taxation law by which the provisions are complex and difficult to understand and reconcile. Moreover, within the tax law contents, it involved the legislation changes with an amount of technical data and interdependent to other sources of legal areas such as Company and Business law. This leads a priority for a study on how students' construct their knowledge in a taxation subject under the traditional teaching and learning approach. The students are often expected the right answer from the course instructor and therefore understanding and applying a right learning approach could be one of assistance to stimulate their knowledge construction.

In the journey of understanding a nature of the taxation subject, determining is whether the taxation subject is a hierarchical-based or horizontal-based knowledge structure is investigated and how it affects the students' learning style. In more specific, the study objective is guided through examination on the types of knowledge structure exists in a taxation subjects. Then, the study assesses on the students' responses on their experience of a Taxation subject. To achieve all study's objectives, the study was carried out at the third year accounting students as a compulsory course for accounting degree.

\section{Literature review}

\subsection{Nature of Taxation -based Subject}

In an accounting curriculum, taxation is one the core subjects with legal implications and the uniqueness characteristics which based on statutes makes the provisions in the main statute is complex, difficult to comprehend and reconcile. In addition, the contents of a taxation subject which directly associated with the legislation changes with an amount of technical data and inter-dependent with other sources of legal areas has led the taxation subject is among the difficult subjects in Accounting degree. For that reason, Martin (2003) indicates her concern on students' knowledge acquisition on this subject is a priority. Therefore, examination on the subject natures through determining a knowledge structure as being a hierarchical or horizontal -based is crucial in tax education.

Although, there is a range of studies discuss on the issue of knowledge structures, but a prominent theorist in this area was introduced by Bernstein (2000). And a discussion of Bernstein theory was acknowledged by a study of Maton and Muller (2007). In this paper, they are highlighted on how Bernstein's thinking theory was developed from the process of pedagogic code to pedagogic discourse in order to form knowledge. Also, in Bernstein theory focuses how education could be understood in its own terms, and without linking with social class relays and other inequalities. Within a similar discussion of Bernstein theory, it was believed that in all subjects, the process of knowledge reproduction in any discipline was engaged in the production, distribution and recontextualization through the text books and curricula planning (Myers, 2016). However, there is an argument in past study such as Moore (2004) which showing the process is not as straightforward.

Further explanation in the Berstein's theory about the structure of knowledge is classified into two types either it is being a hierarchical-type or horizontal-type. For hierarchical knowledge structures, the application is commonly found in Science-based subjects and for humanities discipline is applied a horizontal structure of knowledge. From example, the concise view for hierarchical knowledge structure can be regarded to the knowledge gained under the guidance of an expert. However, a study by Hoadley and Muller (2009) claimed a weak spot of a knowledge structure is when the student's learning is likely to be ceased without further progress. As a consequence, the necessary concept and cumulative learning play a crucial role for students' future learning. When checking on the concept of the hierarchical knowledge structure, a study by Maton (2010) extends the concept of knowledge code to course instructor and the student's knowledge and experience is not play a big role under which only one correct answer would be reachable. Therefore, a horizontal knowledge structure is appropriate as it takes a series of specialized languages with specialized modes of interrogation and specialized criteria for the production and circulation of texts (Bernstein, 1999). This means the knowledge structures for a new concept for is needed for explaining the phenomena because they are linking each other (Myer, 2016). And, at this stage, the course instructor and student knowledge and experience had more valued due to multi-answers would be attainable. 
Another concern with teaching and learning taxation subject is related to the issue of using right material by course instructor and this dedicates to a set of challenges for determining a structure of knowledge in teaching and learning of accounting law-based subjects. As a result, there is an initiative studied on designing and crafting a good problem-based scenario for accounting law-based subjects. For example, a study by Nor Aziah et al. (2011) and Nor Aziah et al. (2013). Based on both studies, the accounting case scenario should consider the problem types and level of courses in order to encourage students' learning skill in the class. By having the similar identified issue in teaching and learning of accounting law-based subjects for accounting students, the quality of case contents also a priority. For example, Nor Aziah et al. (2013) suggest the essential elements for crafting effective problem scenario for a course of the Company Secretarial Practices. They are documented crucial elements which play big roles in the crafted problem scenario should have the element of real life, relevant, authentic, acquire new knowledge, stimulate elaboration and higher order thinking, generate learning issues, engage discussion and exploration, integrate other disciplines, an outcome based, a realistic process, deliverables and resources. All indicated elements were documented in crafting problem-based learning scenario by Barrow (1994) and Temasek Polytechnic (2006). This shows that implementation case scenario for non-law based students by the course instructor could be led to the challenge of teaching and learning among the accounting law-based papers. The reason is teaching and learning the case scenario engaged the inquirybased approach. However, the advantage of applying a case scenario provides the student more opportunity to produce multi answers and solutions. This is clear evidence that using a case scenario in accounting subjects indicates the features of knowledge structure; either it has applied a hierarchical or horizontal knowledge structure although it fits to a specific topic.

Under the accounting curriculum, a taxation subject is known as a legal-based paper under which the students need to be familiar with a conceptual and technical knowledge. Thus, the structure of knowledge within this subject has an implication due to its unique characteristics (Martin, 2003). Accordingly, determination the knowledge structure of a taxation subject, either it has a hierarchical or horizontal is necessary to analyze its following characteristics:

1. As the first characteristic in the taxation subject is based on several statutes such as Income Tax Act 1967, Real Property Gain Tax Act 1976, Promotion Investment Act 1986 and Gazette Orders.

2. The second characteristic in a Taxation subject is regarded with the provisions in the main statute is complex and difficult to be comprehended and reconciled due to rapid changes in legislation and there is an amount of technical data.

3. The third characteristic is regarded for the concepts of taxation subject are inter-dependent with other sources of legal area in the Company Law 1965 and Partnership Act 1961.

For this reason, tracing a literature on tax education is important. In tax education, the process of teaching and learning of a taxation subject applies the same way as similar as other accounting papers (Tan and Veil, 2005). However, the contrasting evidence revealed in few studies carried by using US and UK samples. For example, a study in the US by Gray (1965) found that understanding tax law as most important, nevertheless large exposure to tax concepts to students would be received only partial and fragmented knowledge. Then, later study by Schwartz and Stout (1987) and Sage and Sage (1993) review on a narrow focused in content of a taxation subject has led to believe that a taxation subject is non-related function to other accounting subjects. As a consequence, students who take a taxation subject may fail to relate the broader concept to other disciplines. While in the UK study, as found that the taxation subject is an optional for students, therefore the students' ability is limited to prepare tax computation (Craner and Lymer, 1999). From the above discussion, the findings show the basic understanding of taxation law is sufficient within the context on tax preparation for an individual. Contrasting view revealed by Tan and Veil (2005) indicate that the tax education changed from high technical knowledge to being conceptual orientation is needed for the skill for tax planning, tax avoidance and tax evasion. On one hand, all three essentials knowledge is important to accounting students for their career options. On the other hand, due to increasing cases in tax fraud, an integration of tax evasion and tax avoidance law into an accounting curriculum would be a challenging area for course instructor.

By having the features of a taxation subject, Myers (2016) used a Bernstein theory for to look what the truth and knowledge are in the subject. For example, in a taxation subject, students are commonly 
required to learn the concept of resident status that in a person whether it is classified as a "tax resident person" or "non-tax resident person". From the concept of residence status, students move about on the taxable income classifications and also tax incentives to be granted for a tax resident and a non-tax resident person. Then, the students' progress their understanding to determine the chargeable income and tax bases for income tax computation, either for individual or business taxpayers. This is called a conceptual chain in taxation subject during the second year of study which is that important for a decision about the elements of tax computation. Once having established the fundamental, this would be used as knowledge in further learning into advanced taxation for the third year of study. Furthermore, in the taxation subject, the abstract concept for hierarchical knowledge structures may find in a topic for tax auditing. And this topic would contain of Tax Audit Framework published by the Malaysia Tax Authority in 2007 and passed a series of amendments in the year of 2013, 2015 and 2017. There are five areas in the tax audit framework and that is:

1. Statutory provisions for tax audit.

2. Objective of tax audit.

3. Process of tax audit.

4. Rights and Responsibilities of tax authority and taxpayer.

5. Offences and Liabilities.

Discussion about the concept of income classifications, incentives provided and tax computation are related to an area of the framework, therefore the knowledge is relevant and to be one the truth. Then, the process of discussion about Tax Audit Framework was first introduced in the class slot in order to increase students' understanding the statutory provisions and right and responsibility of the tax authority and the taxpayer. For any non-compliance behavior with statutory provision, this subjects to the offences. From the analysis of a taxation subject, it is very clear that the subject has a hierarchical knowledge structure as the concept of finding one truth applied in the course as equal as in financial accounting. Also, it shows the prior knowledge within accounting subjects play a crucial role in creating the new knowledge of Taxation. Furthermore, inability to understand the previous concept, the student is likely to engage in a problematic for the next concept.

\section{Methodology of Research}

The first stage of study was constructed based on the Bernstein theory (2000) to analyze the types of knowledge structure have in a taxation subject, either it is a horizontal or hierarchical knowledge structures. Then, the second stage of study is for determining the implication of knowledge structure on students' achievement in this subject. This is a consequence of the nature of a taxation subject which is inter-dependent with other sources of statutes. Details of the process for a data collection is all registered students for Taxation II were participated in this study through completion of an online questionnaire. However, the sample selection which was divided into three predetermined levels of academic performance in the June 2019 examinations, race and gender. The process of sample selection follows the similar approach as applied by Myers (2016) to facilitate comparison and compare differences between how students constructed knowledge within the three groupings of academic performance, race and gender. Then, the students were divided based their academic groups of less successful (did not pass with the overall mark less than 50\%), moderately successful (had passed with overall marks of between $50 \%$ and $69 \%$ ) and very successful (had obtained a final mark of $70 \%$ or higher). Finally, the semi-structured questionnaire took place at the end of a semester and all students were asked the same questions which were framed in the research question which was:

1. How do students construct knowledge in a taxation subject?

2. What techniques you use to help you better understand taxation?

The main aim of both questions is to identify how students constructed knowledge of taxation and whether or not they understood that the foundation of taxation is based on conceptual and technical knowledge. Only the students very successful (had obtained a final mark of $70 \%$ or higher) to the question were selected. The main reason is a successful student response would reveal whether students used any learning aids such as a graphical organizer to understand new topics in the subject. Also, this allowed determining whether or not the students were aware of the taxation concepts and identifying whether or 
not they understood that some processes needed to legal statutes. This is an approach to determine whether the students were developing an expert eye when reading tax questions.

For data analysis, the study used thematic text analysis, and this considers useful for study context through pre-identification themes and the representation of the themes (Evans, 2018). Then, the themes have been grouped based on the students' responses which were initially grouped according to the academic group, race and gender. The differences in how students constructed knowledge were noted between students within the successful academic group. As the study took place with limited controls and in an open environment, this is necessary to consider issues or the potential for bias of data. Based on the past study highlighted by Myers (2016), the potential bias could be affected into three areas include selection bias (Collier and Mahoney, 1996), where certain students are more likely to participate in a research project. As successful students in taxation class to be part of research, the selection bias should not be a threat to the validity and reliability of this research. The second threat is response bias (Furnham, 1986), where a participant in research provides a response as they believe to be 'correct'. As this research was an investigation into the way students constructed knowledge, so there were no correct or incorrect responses, and response bias should not be a threat to the reliability of this research. And the third bias could be dedicated to researcher bias (Bailar et al., 1977), which occurs where the researcher has formed an opinion about a participant prior to the data collection. As this aspect was made to avoid leading participants and ensure that participants' responses were not anticipated prior to the semi-structured questionnaire distributions, so it is not be a threat to the reliability of this research.

\section{Study's Findings}

\subsection{The Structure of Knowledge in Taxation Subject}

To answer the first research objective on determining whether the taxation subject is a hierarchical or horizontal or could be a combination of knowledge structures, so the examination for the element of truth and knowledge is important. In the taxation subject, the formal teaching by a course instructor is needed where the students first learn that in every tax preparation is a residence status. This is because the understanding the residence status concept allows students to proceed with income, tax incentives and tax rates applicable. This called a conceptual knowledge which is taught in the Principle of Taxation (Taxation 1). At the stage, all students are learned basic knowledge on which they make a decision on tax computation. Then, the knowledge is accumulated and integrated in further learning for Taxation II (Advanced Taxation). For example, the conceptual knowledge and the technical knowledge (legal statues) could be found when the students learn the topic for tax auditing. As the topic contains Tax Audit Framework and students are required to acknowledge all the amendments by the tax authority. As a result, a truth about a taxation subject is based on similar regulatory framework and other legal statutes as similar students are working with tax computations. The analysis for a taxation subject nature, it has a systematic structure of knowledge and based on specific principle. When students studied taxation, they are relied on previous knowledge to be incorporated in new knowledge. Without understanding the concept, students unlikely to progress to the next concept and this leads to a problematic to the topic. The analysis shows that knowledge structure of a taxation subject could be explained in a hierarchical due to one correct solution is allowed (one truth).

\subsection{The Students Knowledge Construction and Academic Achievement in a Taxation Subject}

For the second objective is to analyze on how the student constructed their knowledge in a taxation subject through knowledge acquisition in the examination, the pre-identification theme of student learning technique was determined according to following points:

- Knowledge construction of learning taxation is based on one correct answer.

- In the process of attaining one correct answer, students need to master over the procedures which can be achieved through understand the correct format. This understanding required for distinguish the tax treatments. At this point, students are becoming skillful in answering a question by putting the correct answer in the format.

As study discussion that follows the successful academic grouping to which the students are who had achieved a final mark of $70 \%$ or higher. Therefore, the students were ranked from the highest scores to the 
lowest in examination. The responses are provided as a taxation subject is a hierarchical knowledge structure which is based one correct answer. There are nine responses that being successful was understand the tax subject is a computational based and provide one answer which can be achieved via understanding the correct format. The nine successful students were able to apply it to different tax scenarios. Then, the theme was continued with their learning style as the students were asked how they were obtained the new concept in a taxation subject, particularly about the techniques which they used to better understand technical procedures. Most of the successful students use a visual learning through mind-mapping and colorful short-notes. This technique is accepting technique for connecting the conceptual and technical information. The students also applied a background reading for searching early information through reading and browsing information about the topic. Other learning techniques used by the successful students in taxation subject are creating study group and learning through examples. However, some students were preferred to apply Socratic learning techniques when answering a tax question. From the finding, it shows that successful students seemed to have an understanding that there is one truth in answering a tax question, and connecting conceptual with technical information are crucial. Further analysis also shows an awareness of actively practicing early reading and past examples; they were demonstrating a low-road transfer.

\section{Conclusions}

On the whole, most students in a successful group demonstrated a high level of competency in the knowledge acquisition of a taxation subject. As a successful student group had successfully understood the knowledge structure in the tax discipline by allowing a low-road transfer. Also, the student's responses explain of how they constructed tax knowledge through their learning techniques. Given this lens through the student's view validated by what was seen in their examination result. The finding of the study provides understanding of how students constructed their knowledge in any legal-based paper with a hierarchical knowledge structure. From the study outcomes, it is expected to benefit course instructor for improving pedagogical approach and producing a proper documentation (procedures) on the relevancy of student knowledge constructions for law-based subjects in accounting. This also added a value to course instructor in guiding moderate or less successful students in the various techniques which are required for constructing knowledge in this subject.

\section{Acknowledgement}

This research is supported by the Research Management Centre of the Universiti Pendidikan Sultan Idris under the Short-Term Grants (GPU-2018-0021-107-01).

\section{References}

1. Bailar, B., Bailey, L., \& Stevens, J. (1977). Measures of interviewer bias and variance. Journal of Marketing Research, 14(3), 337-343.

2. Barrows, H, S. (1994). Problem-based Learning. Problem-based learning applied to medical education. Illinois: Southern Illinois University School of Medicine.

3. Bernstein, B. (1999). Vertical and horizontal discourse: An essay. British Journal of Sociology of Education, 20(2), 157-173.

4. Bernstein, B. (2000). Pedagogy, Symbolic Control, and Identity: Theory, Research, Critique (Rev.ed.). Lanham, Md: Rowman \& Littlefield Publishers.

5. Blechova, B. \& Sobotovicova, S. (2015). Analysis of Tax Education in a Business School: a Case Study. Periodica Polytechnica Social and Management Sciences, 24(2). 113-118.

6. Boldt, M. N. (2001).Assessing Student's Accounting Knowledge: A Structural Approach. Journal of Education for Business, 76(6), 262-269.

7. Bradford, S., \& Cullen, F. (2012). Research and research methods for youth practitioners. London: Routledge.

8. Colburn, A. (2000). An inquiry primer. Science Scope, 42-44.

9. Collier, D., \& Mahoney, J. (1996). Insights and pitfalls: Selection bias in qualitative research. World Politics, 49(1), 56-91. 
10. Douglas, S. (2012). Student engagement, problem based learning and teaching law to Business students. E-Journal of Business Education \& Scholarship of Teaching, 6 (1), 33-47.

11. Evans, C. (2018). Analyzing Semi-Structured Interviews Using Thematic Analysis: Exploring Voluntary Civic Participation among Adults. London: SAGE Publishing.

12. Flick, U. W. E. (2009). An introduction to qualitative research. London: SAGE Publishing.

13. Furnham, A. (1986). Response bias, social desirability and dissimulation. Personality and Individual Differences, 7(3), 385-400.

14. Hoadley, U., \& Muller, J. (2009). Codes, pedagogy and knowledge: Advances in Bernsteinian sociology of education. In M. W. Apple, S. J. Ball, \& Armando Gandin, Luis (Eds.), The Routledge International Handbook of the Sociology of Education, London; New York: Routledge.

15. Martin, F. (2003). Using a Modified based learning approach to motivate and enhance learning in taxation law. The Law Teacher, 37(1), 55-75.

16. Maton, K. and Muller, J. (2007). A Sociology for the Transmission of Knowledges. In Language, Knowledge and Pedagogy. Functional Linguistic and Sociological Perspectives, ed. F. Christie and J.R. Martin, (pp.14-33). London: Continuum.

17. Maton, K. (2010). Analysing knowledge claims and practices: Languages of Legitimation. In K. Maton \& R. Moore (Eds.), Social Realism, Knowledge and the Society of Education: Coalitions of the Mind (pp. 35-59). London: Continuum.

18. Myers, L. P. (2016). Knowledge structures and their relevance for teaching and learning in introductory financial accounting. South African Journal of Accounting Research, 30(1), 75-95.

19. Myers, L. P. (2017). An analysis of how students construct knowledge in a course with a hierarchical knowledge structure. South African Journal of Accounting Research, 31(31), 193-211.

20. Newlyn, D., \& Spencer, L. (2010), Improving Student Performance in Interdisciplinary Law Unit Assessment by Providing Annotated Exemplars. Journal of the Australasian Law Teachers Association, 3(1), 67-75.

21. Aziah, N. A. M., Zuaini, I. and Nordin, W. H. (2011). Application of PBL in Financial Accounting Principles Course. Malaysian Journal of Learning and Instruction (MJLI), 8, 21-47.

22. Aziah, N. A. M., Zuaini, I., Zahyah, H., \& Sofia, M. Y. (2013). Crafting A Good PBL Scenario in Company Secretarial Practices Course, The paper presented in The 4th International Research Symposium on Problem-Based Learning (IRSPBL).

23. Ramsden, P. (2005). Learning to Teach in Higher Education, 2nd ed., Routledge Falmer. 